\title{
AN APPROACH TO KY FAN TYPE INEQUALITIES FROM BINOMIAL EXPANSIONS
}

\author{
JAMAL ROOIN
}

Abstract. In this article, using binomial expansions, we get some interesting recursive identities concerning arithmetic, geometric and harmonic means of positive numbers, from which, the most important Ky Fan type inequalities are handled by induction at once.

Mathematics subject classification (2000): 26D15, 26A06.

Key words and phrases: Binomial expansion, Mean value theorem.

\section{REFERENCES}

[1] H. Alzer, Inequalities for arithmetic, geometric and harmonic means, Bull. London Math. Soc., 22 (1990), 362-366.

[2] H. Alzer, The inequality of Ky Fan and related results, Acta Appl. Math., 38 (1995), 305-354.

[3] H. ALzER, Ungleichungen für geometrische und arithmetische Mittelwerte, Proc. Kon. Nederl. Akad. Wetensch., 91 (1988), 365-374.

[4] E.F. BeCKenbach and R. Bellman, Inequalities, Springer-Verlag, Berlin, 1961.

[5] P.S. Bullen, D.S. Mitrinović And P.M. Vasić, Means and their inequalities, Reidel, Dordrecht, 1988.

6] E. HewitT AND K. STROMBerG, Real and abstract analysis, Springer-Verlag, New York, 1975.

[7] J. RooIN, AGM inequality with binomial expansion, Elemente Der Mathematik, 58 (2003), 115-117.

[8] J. Roorn, Ky Fan's inequality with binomial expansion, Elemente Der Mathematik, 60 (2005), 171-173.

[9] W.L. WANG AND P.F. WANG, A class of inequalities for the symmetric functions (in chinese), Acta Math. Sinica, 27 (1984), 485-497. 